\title{
Gene Dosage and Complementation Analysis of the Shaker Locus in Drosophila
}

\author{
Leslie C. Timpe and Lily Y. Jan \\ Howard Hughes Medical Institute and Department of Physiology, University of California, San Francisco, San Francisco, \\ California 94143
}

\begin{abstract}
Mutations of the Shaker (Sh) locus alter or eliminate a transient, voltage-sensitive potassium current, the "A" current, in flight muscle of Drosophila. We show that the amplitude of the A current is reduced when the dosage of $\mathrm{Sh}^{+}$is lower than normal, but that $A$ current amplitude does not increase as extra copies of $\mathrm{Sh}^{+}$are added. We have also examined 14 Shaker mutants by voltage clamp and by intracellular recording at the larval neuromuscular junction. In 10 of these mutants there is no detectable fast component of the transient outward current. In each of these 10, however, a small, slowly inactivating, outward current is present. The $10 \mathrm{mu}$ tations null for the fast component of the transient, outward current are all partially dominant, giving $50-80 \%$ of the normal A current in $\boldsymbol{S h}^{\text {null }} / \boldsymbol{S h}^{+}$heterozygotes. Because as little as $5 \%$ of the normal A current can be detected, complementation tests are feasible. The 10 null mutations are members of a single complementation group. The remaining 4 mutations have reduced $A$ currents in pupal flight muscle. In all cases, crosses between these leaky mutants and null mutants give progeny with less $A$ current than found in the leaky parental lines, as would be expected if the leaky and null mutations are in the same complementation group. For 1 of the mutations, $S h^{\text {rKo } 120, ~ t h e ~ m u t a n t ~ p h e n o t y p e ~ i s ~ m u c h ~}$ more severe in nerve than in muscle. That part of the Shaker locus required for the production of the $A$ channel lies between the $B 55$ and the $V 7$ translocation breakpoints, in region $16 \mathrm{~F}$ of the $X$ chromosome.
\end{abstract}

The ionic currents that underlie electrical excitability in nerve and muscle have been examined in great detail with neurophysiological techniques, but the channels through which these currents flow have been difficult to isolate and study biochemically. As a result, little is known about the structure of these molecules or about the control of their expression and membrane localization. Initially, the vertebrate nicotinic $\mathrm{ACh}$ receptor and the voltage-sensitive sodium channel were purified by use of affinity reagents or neurotoxins as ligands (Henderson and Wang, 1972;

\footnotetext{
Received July 16, 1986; revised Oct. 27, 1986; accepted Oct. 31, 1986.

We would like to thank Dr. B. Ganetzky for his gift of Shaker mutants, Drs. John Belute, Bruce Baker, and Ian Duncan for help with chromosome squashes, and Drs. E. Grell, R. Greenspan, and T. Schwarz for their comments on the manuscript. This work was supported by a Muscular Dystrophy Association Postdoctoral Fellowship (L.C.T.), by the Howard Hughes Medical Institute, and by NIH Grant RO1 NS15963.

Correspondence should be addressed to Leslie C. Timpe, Howard Hughes Medical Institute, University of California, San Francisco, Third Avenue and Parnassus, Box 0724, San Francisco, CA 94143.

Copyright (C) 1987 Society for Neuroscience $0270-6474 / 87 / 051307-11 \$ 02.00 / 0$
}

Weill et al., 1974). More recently, alternative approaches, employing recombinant DNA techniques, have also been used to begin the molecular analysis of the $\mathrm{ACh}$ receptor and of the sodium channel (Noda et al., 1984; Mishina et al., 1985). The experiments to be described here are part of an effort to identify the gene for one type of voltage-sensitive potassium channel, the " $\mathrm{A}$ " channel, so that the gene and its gene product may be studied molecularly even though no high-affinity ligand is currently available for this channel. Mutations of the Shaker $(S h)$ locus in Drosophila melanogaster alter or eliminate the A current in pupal indirect flight muscle (Salkoff and Wyman, 1981b). This and other neurophysiological observations prompted the suggestion that the product of the Shaker locus is the A channel, or a subunit of it (Salkoff and Wyman, 1981a; Jan et al., 1983). To test this hypothesis further we have asked whether the amplitude of the A current follows gene dosage, as would be expected if Shaker were the structural gene for the A channel. In addition, we have examined several Shaker mutations using voltage-clamp and intracellular recording techniques. The purpose has been to characterize the different phenotypes of Shaker mutants, to study the genetic complexity of the Shaker region with complementation tests, and to locate Shaker vis-à-vis several previously described translocation breakpoints.

Mutations of the Shaker locus cause lightly etherized flies to shake their legs and scissor their wings (Kaplan and Trout, 1969). Jan et al. (1977) discovered that synaptic transmission at the neuromuscular junction of Shaker larvae is abnormal and proposed that the mutant phenotype is due to a defective potassium channel in the membrane of the motoneuron's axonal terminal. Support for this hypothesis came from Tanouye et al. (1981), who observed that the repolarization of the action potential in the cervical giant fiber is delayed in Shaker flies, and from Salkoff and Wyman (1981b), who showed that a transient, voltagesensitive potassium current is missing from the pupal indirect flight muscle of certain Shaker mutants. This potassium current, called A current because of its resemblance to a current originally characterized in molluscan neurons (Connor and Stevens, 1971; Neher, 1971), can be distinguished from several other potassium currents normally present in pupal muscle (Salkoff and Wyman, 1981a; Salkoff, 1983a). The evidence that Shaker may be a structural gene for the A channel includes a study of the effect of gene dosage on action potential duration in cervical giant fibers (Tanouye et al., 1981) and the observation that 1 allele, $S h^{5}$, alters the kinetics of A current inactivation (Salkoff and Wyman, 1981b).

The most direct and sensitive method for studying the Shaker phenotype is to examine the A current by means of the voltage 


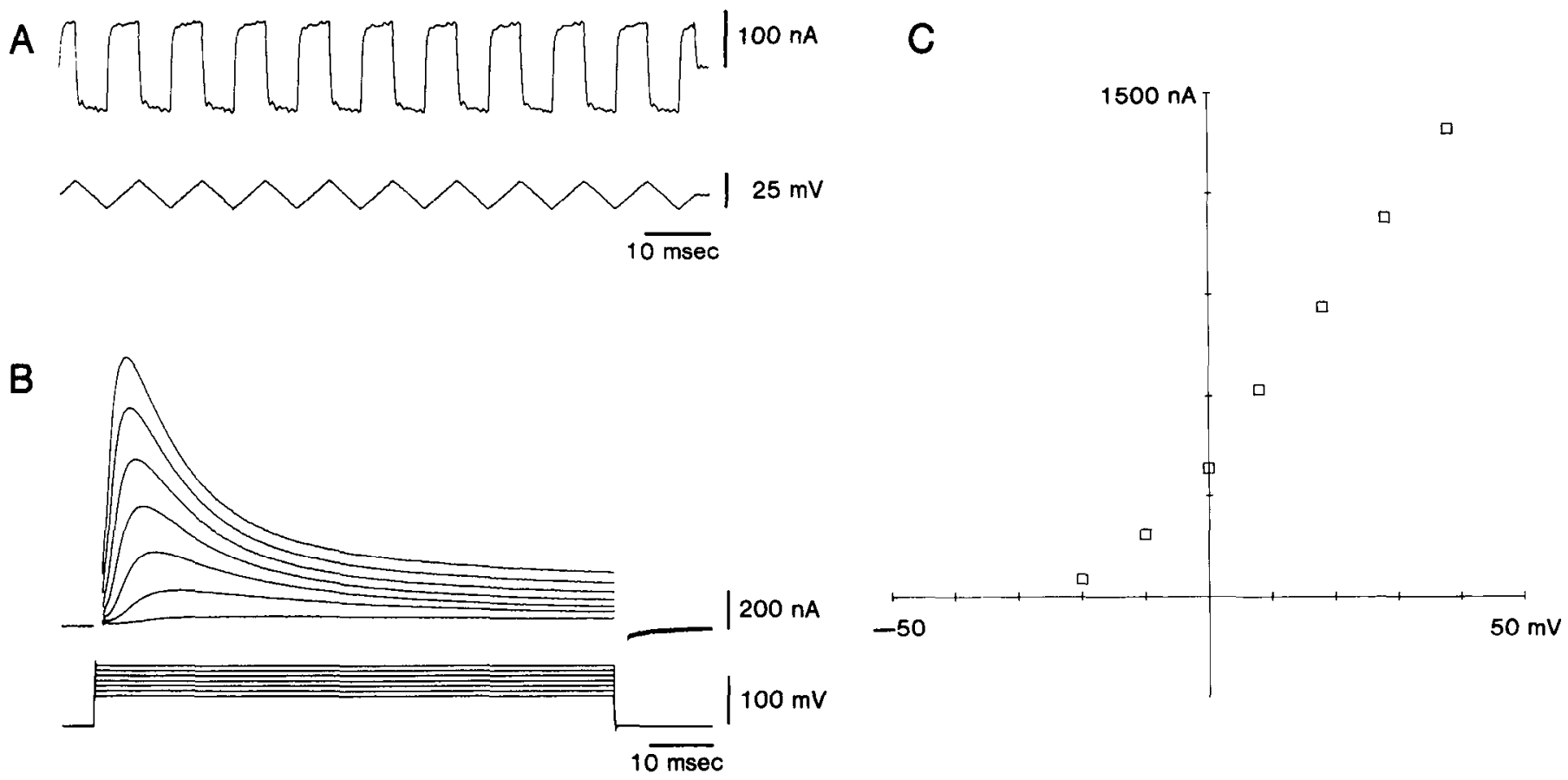

Figure 1. Measurement of membrane capacitance, peak A current, and approximate slope conductance. $A$, Sawtooth command is applied to a voltage-clamped membrane held at $-80 \mathrm{mV}$. Upper trace, Membrane current. The capacitative current $\left(I_{c}\right)$ is the difference between the "peaks" and the "troughs." Membrane capacitance was calculated from $C=I_{c} /(2 \times d V / d t)$. In this case, $C=18.0 \mathrm{nf}$. Lower trace, Membrane potential follows the sawtooth command. $B$, The A current measured in the same fiber as in $A$. Jumps were from $-80 \mathrm{mV}$ to a range of potentials from -20 to $+38 \mathrm{mV}$. Each trace is the average of 4 . Linear leakage current, determined from hyperpolarizing jumps, has been subtracted. To maintain adequate voltage control during the A current peak, the voltage-clamp gain was turned up to approximately $10^{4}$. As a result, the membrane potential rang for a few milliseconds after a jump. The ringing artifacts have been deleted from the current traces. $C$, Current-voltage relation of the peak A currents from $B$. The approximate slope conductance between the points at +18 and $+38 \mathrm{mV}$ is $26.4 \mu \mathrm{S}$. $\Gamma$ for this fiber is therefore $1.47 \times$ $10^{-3} \mathrm{~S} / \mathrm{cm}^{2}$, assuming $1 \mu \mathrm{f} / \mathrm{cm}^{2}$.

clamp. The amplitude of a macroscopic current is directly proportional to the number of ion channels in a nerve or muscle cell's membrane. The A current's amplitude is therefore a measure of expressivity and should be well-suited for gene-dosage experiments. Furthermore, voltage-clamp studies may reveal subtle alterations in current kinetics (Salkoff and Wyman, 1981b), which might be overlooked by the more indirect tests of simple intracellular recording. Of the several dozen Shaker mutants known, however, only a few have been studied by voltage clamp (Salkoff and Wyman, 1981b; Jan et al., 1983; Salkoff, 1983b). Using the 2-microelectrode voltage-clamp technique, we have examined 14 different mutations of Shaker. The mutants fall into 2 phenotypic classes: mutants with no detectable A current, and those with reduced A current. One mutant, $S h^{\text {rKO } 20}$, appears to alter the expression of the Shaker product differently in nerve and muscle. The 10 mutants that lack A current are members of a single complementation group.

\section{Materials and Methods}

Voltage clamp of pupal muscle fibers. Pupae were removed from their cases, pinned with the ventral side up on a slab of clear resin (Sylgard, Dow Corning), and slit along the midline of the thorax. Using forceps and dissection scissors, the cuticle and body wall musculature were trimmed down to the horizontal midline. The ventriculus, salivary glands, aorta, and thoracic ganglion were then removed, exposing 4 of the 12 dorsolongitudinal flight muscles; these are the fibers whose currents were studied. Previous experiments of Salkoff and Wyman (1983) have shown that the dorsolongitudinal flight muscle fibers, roughly $1000 \times 80 \times 50$ $\mu \mathrm{m}$, are isopotential.

For gene-dosage experiments the fibers were clamped using an Axon Instruments Axoclamp-2; current was measured through a virtual ground current monitor. The current signal was filtered at $1-3 \mathrm{kHz}$ with an 8-pole low-pass Bessel filter. Voltage and current traces were digitized with $100 \mu$ sec sample interval by a 12-bit A/D converter, then analyzed on a PDP $11 / 73$ computer. The remainder of the experiments were done with a simple voltage-clamp circuit and virtual ground monitor constructed from designs kindly provided by Dr. A. J. Hudspeth. Muscle fibers were penetrated with two 3-5 $\mathrm{M} \Omega$ microelectrodes. The currentinjecting eletrode was painted first with colloidal silver, then with insulating varnish, to make a grounded shield. To maintain a stable holding current it was important that the micropipettes be filled with $4 \mathrm{M}$ potassium acetate rather than with potassium chloride. The normal saline solution contained (in mM) $40 \mathrm{KCl}, 57 \mathrm{Na}_{2} \mathrm{SO}_{4}, 21 \mathrm{MgSO}_{4}, 10$ glucose, 96 sucrose, and 5 HEPES adjusted to $\mathrm{pH} 7.0$. The composition of this solution is based on that of Drosophila larval hemolymph (Begg and Cruikshank, 1962), with the exception that $\mathrm{Ca}^{2+}$ is omitted. To maintain extracellular [ $\left.\mathrm{Cl}^{-}\right]$near $40 \mathrm{mM}$, as in larval hemolymph, $\mathrm{SO}_{4}{ }^{2-}$ was used as an anion in addition to $\mathrm{Cl}^{-}$. All voltage-clamp experiments were carried out at $12 \pm 1^{\circ} \mathrm{C}$.

In the normal development of dorsolongitudinal flight muscle, the A current first appears $55 \mathrm{hr}$ after formation of the puparium and then increases until hour 72 (Salkoff and Wyman, 1981a). At that time, the delayed rectifier, or $\mathrm{K}$ current, begins to appear. In the experiments reported here, the $A$ current was studied in the absence of $K$ current by selecting pupae approximately $72 \mathrm{hr}$ after pupation.

Synaptic transmission at the larval neuromuscular junction. Third instar larvae were selected and dissected as described by Jan and Jan (1976). After dissection and pinning out on Sylgard, the preparation forms a sheet of larval cuticle covered by body wall musculature. A separate segmental nerve innervates the muscle fibers of each left and right half body segment. These nerves were severed near their insertions into the ventral ganglion and the cut ends taken up into a suction electrode for stimulating the axons of the motor neurons extracellularly (Jan and Jan, 1976). Microelectrodes of 10-30 M $\Omega$ tip resistance, filled with $3 \mathrm{M} \mathrm{KCl}$, were used for recording intracellularly from muscle fibers. At $5 \times 10^{-5} \mathrm{M} \mathrm{Ca}^{2+}$ excitatory junctional potentials may be elicited in Shaker mutants, but not in wild-type larvae (Jan et al., 1977; Ganetzky and $\mathrm{Wu}, 1982)$. The experiments on larval neuromuscular junction 


\begin{tabular}{|c|c|c|c|c|c|}
\hline Genotype & $\begin{array}{l}\text { Copies } \\
\text { of } S h^{+}\end{array}$ & Sex & $\begin{array}{l}S h^{+} \text {dosage, } \\
\text { compensated } \\
\text { for sex }\end{array}$ & $\begin{array}{l}\Gamma \text { observed, } \\
\left(\times 10^{-3} \mathrm{~S} / \mathrm{cm}^{2}\right)\end{array}$ & $\begin{array}{l}\Gamma \text { expected, assuming } \\
\text { proportionality to dosage }\end{array}$ \\
\hline $\mathrm{Df}(1) \mathrm{JC} 153 / \mathrm{T}(1 ; \mathrm{Y}) \mathrm{W} 32^{\mathrm{P}} / \mathrm{X}^{\mathrm{OR}}$ & 1 & q & 1 & $\begin{array}{l}1.02 \pm 0.31 \\
n=10\end{array}$ & $\begin{array}{l}0.77 \\
\left(1 / 2 \Gamma \text { for } X^{\mathrm{OR}}\right)\end{array}$ \\
\hline Oregon R ( $\delta \hat{o}+q q)$ & & & 2 & $\begin{array}{l}1.53 \pm 0.25 \\
n=11\end{array}$ & \\
\hline$\hat{\partial} \hat{B}$ & 1 & $\hat{o}$ & 2 & $\begin{array}{l}1.59 \pm 0.27 \\
n=6\end{array}$ & \\
\hline की & 2 & $q$ & 2 & $\begin{array}{l}1.46 \pm 0.23 \\
n=5\end{array}$ & \\
\hline $\mathrm{C}(1) \mathrm{A}$ & 2 & $q$ & 2 & $\begin{array}{l}1.37 \pm 0.40 \\
n=10\end{array}$ & \\
\hline $\mathrm{T}(1 ; \mathrm{Y}) \mathrm{B} 55^{\mathrm{D}} / \mathrm{T}(1 ; 4) \mathrm{B}^{\mathrm{SP}}$ & 1 & $\delta$ & 2 & $\begin{array}{l}1.33 \pm 0.22 \\
n-9\end{array}$ & \\
\hline $\mathrm{C}(1) \mathrm{A} / \mathrm{T}(1 ; 4) \mathrm{B}^{\mathrm{SP}}$ & 3 & $q$ & 3 & $\begin{array}{l}1.39 \pm 0.23 \\
n=10\end{array}$ & $\begin{array}{l}2.04 \\
{[\Gamma \text { for } C(1) \mathrm{A}+1 / 2 \Gamma} \\
\left.\quad \text { for } \mathrm{T}(1 ; \mathrm{Y}) \mathrm{B} 55^{\mathrm{D}} / \mathrm{T}(1 ; 4) \mathrm{B}^{\mathrm{sP}}\right]\end{array}$ \\
\hline $\mathrm{X}^{\mathrm{OR}} / \mathrm{T}(1 ; 4) \mathrm{B}^{\mathrm{SP}}$ & 2 & $\hat{o}$ & 4 & $\begin{array}{l}1.68 \pm 0.48 \\
n=11\end{array}$ & $\begin{array}{l}2.86 \\
{\left[\Gamma \text { for } \mathrm{X}^{\mathrm{OR}}+\Gamma\right.} \\
\left.\quad \text { for } \mathrm{T}(1 ; \mathrm{Y}) \mathrm{B} 55^{\mathrm{D}} / \mathrm{T}(1 ; 4) \mathrm{B}^{\mathrm{SP}}\right]\end{array}$ \\
\hline
\end{tabular}

Amplitude of A current as a function of $S h^{+}$dosage. $\Gamma$ was measured as in Figure 1. The symbol "XoR" refers to the $X$ chromosome from the Oregon $R$ control stock.

reported here were all carried out in a low- $\mathrm{Ca}^{2+}$ saline, containing (in mM) $128 \mathrm{NaCl}, 2 \mathrm{KCl}, 35.5$ sucrose, 5 HEPES, $10 \mathrm{EDT} \Lambda, \mathrm{MgCl}_{2}$ and $\mathrm{CaCl}_{2}$ added to give $4 \mathrm{~mm}$ free $\mathrm{Mg}^{2+}$ and $0.05 \mathrm{~mm}$ free $\mathrm{Ca}^{2+}$, adjusted to $\mathrm{pH} 7.0$.

Mutant strains. Table 2 lists the various mutants of $D$. melanogaster studied. Oregon $R$ was the wild-type used for $S h^{+}$controls, except as noted in the gene-dosage experiments. The mutants $S h^{\mathrm{K} 82 \mathrm{a}}, S h^{\mathrm{K} 82 \mathrm{~b}}, S h^{\mathrm{P}}$, and $S h^{\mathrm{K} 83 \mathrm{~s}}$, which have not been described before, were provided to us very generously by Dr. B. Ganetzky. To see if any of these mutations were caused by a gross chromosomal rearrangement, squashes of polytene chromosomes from larval salivary glands were examined. For $S h^{\mathrm{k} 82 \mathrm{~b}}$, $S h^{\mathrm{P}}$, and $S h^{\mathrm{K} 83 \mathrm{r}}$ the $X$ chromosome was intact and the $16 \mathrm{~F}$ region, previously identified as the site of Shaker (Tanouye et al., 1981), appeared to be normal. In squashes of salivary glands from $S h^{\mathrm{K} 82 \mathrm{a}}$, however, region $16 \mathrm{~F}$ is found to be pulled into the chromocenter, while the proximal portion of the $X$ chromosome forms a small loop (T. L. Schwarz, personal communication). The nature of this rearrangement is still under investigation. Preliminary experiments with $S h^{\mathrm{SB} 2}, S h^{\mathrm{SB} 3}$, and $S h^{\mathrm{SB} 13}$ have been described by Jan et al. (1983). Translocation stocks B55, W32, and V7 (Stewart, 1973) were obtained from Dr. J. Merriam.

Aneuploid genotypes for the gene-dosage experiments were created as follows. The proximal element of $T(I ; 4) b^{\text {s }}\left(I(I ; 4) b^{\text {sP }}\right)$ extends to $B^{\text {s }}$ and thus includes Shaker (Lindsley and Grell, 1968). This fragment of the $X$ chromosome was maintained in a stock with the distal element of $T(1 ; Y) B 55\left(T(I ; Y) B 55^{\circ}\right)$ and a compound $X, C(I) A$ (Lindsley and Grell, 1968). Roughly half the females had bar eyes; these females were of the genotype $\left(T(1 ; 4) B^{\mathrm{SP}}\right) / C(l) A$, and carried 3 doses of Shaker. Bareyed females of genotype $\left(T(1 ; Y) B 55^{\mathrm{D}}\right) / C(1) A$, with only 2 doses of Shaker, might also be produced by this cross. These metafemales are rarely observed in the stock, however, and it is unlikely that any were mistaken for $\left(T(1 ; 4) B^{\mathrm{SP}}\right) / C(1) A$ females. Bar-eyed males with 2 copies of Shaker were obtained from the cross $\left(T(1 ; 4) B^{\mathrm{SP}} /\left(T(1 ; Y) B 55^{\mathrm{D}}\right)\right.$ males $\times$ Oregon $\mathrm{R}$ females. Female pupae with 1 dose of Shaker were products of the cross $D f(1) J C 153 / F M 7 a /\left(T(1 ; Y) W 32^{\mathrm{P}}\right)$ females $\times$ Oregon $\mathrm{R}$ males. The pupae with 1 dose of Shaker had no bar phenotype. The proximal element of $T(I ; Y) W 32$ was required to complement the haplolethality of $D f(1) J C 153$ (Tanouye et al., 1981). Males with both elements of the W32 translocation have no detectable A current (Table 2). The deficiency $D f(I) J C 153$ was obtained from the insertional translocation $T(1 ; 3) J C 153=16 E 2-4 ; 17 A-B ; 99 D$.

One of the Shaker mutants studied by Jan et al. (1977), $S h^{\text {rко120, has }}$ since been shown to be a double mutant (Ganetzky and Wu, 1983). The second mutation is an allele of ether-a-go-go (eag), at map position 48.9 on the $X$ chromosome. In the experiments to be described here, "ShrKO120" will refer to the Shaker component of the double mutant, scparated by recombination by Dr. C. Laffer in this laboratory.

\section{Results}

If $S h$ is a structural gene for the A channel, the severity of the Shaker phenotype should be proportional to the number of doses of $\mathrm{Sh}^{+}$(O'Brien and MacIntyre, 1978). Tanouye et al. (1981) have reported that both the duration and the number of evoked action potentials in the cervical giant fiber increase as the dosage of $S h^{+}$is reduced. The relationship between action potential duration and A channels is not simple, however, since sodium channel inactivation and the aclivation of other potassium channels also influence spike repolarization. Moreover, no quantitative comparison was made between the phenotype and the number of doses of $S h^{+}$in those experiments. We decided to reexamine the effects of altering $S h^{+}$dosage, using the amplitude of A current in pupal indirect flight muscle as a measure of the expression of Shaker.

\section{Measurement of A current amplitude}

Preliminary experiments on a wild-type control, Oregon $R$, showed considerable variation in peak A current amplitude. In a sample of 11 fibers the peak $A$ current evoked by a jump to $28 \pm 1 \mathrm{mV}$ was $895 \mathrm{nA}$, with a standard deviation of $287 \mathrm{nA}$, or $32 \%$ of the mean. As we intended to make a quantitative study of the relation between the dosage of $S h^{+}$and A current amplitude, it seemed important to try to identify the sources of this variation, and perhaps to reduce it. Two factors that might contribute to the error are variation of the potassium equilibrium potential $\left(E_{\mathrm{k}}\right)$ between fibers and variation in fiber size. Since the current seen in response to a voltage jump is proportional to the difference between the jump potential and the current's reversal potential $\left(E_{\mathrm{R}}\right)$, differences in $E_{\mathrm{K}}$, which would alter $E_{\mathrm{R}}$ for the A current, are a potential source of variation. 


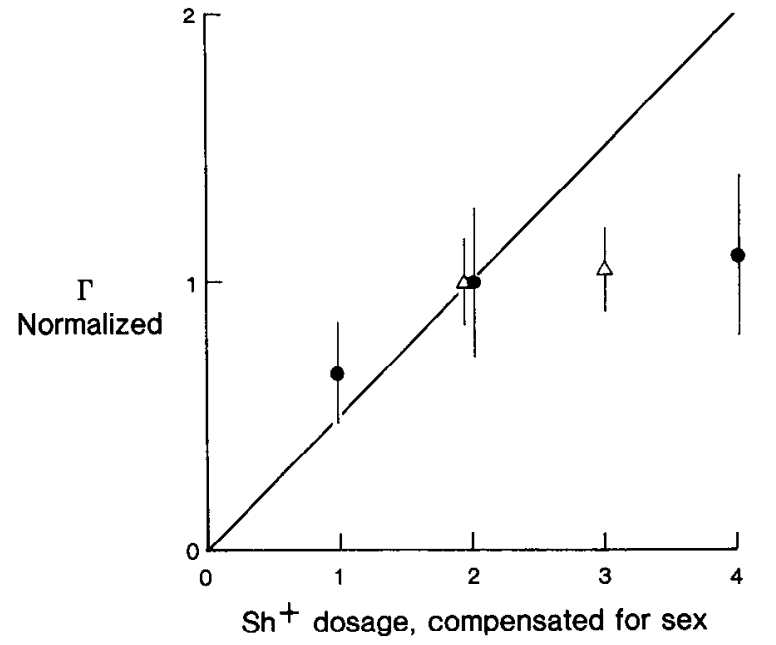

Figure 2. Summary of gene-dosage results. $\Gamma$ has been normalized to the value found in Oregon $R$ controls (filled circles) or in $C(I) A$ controls (open triangles). The diagonal line is the relation expected if $\Gamma$ were proportional to the dosage of $\mathrm{Sh}^{+}$. Error bars are SDs.

We tried to reduce this error by measuring the approximate slope conductance from the peak current-voltage relation at positive potentials (Fig. 1). The approximate slope conductance (G) should be directly proportional to the number of A channels in the membrane, but insensitive to shifts in the A current's reversal potential. When the approximate slope conductances of the same 11 Oregon $R$ fibers cited above were measured, they were found to average $21.7 \pm 6.1 \mu \mathrm{S}$, a standard deviation of $28 \%$. Thus, the measurement of approximate slope conductance achieved only a small reduction in the SD. Inspection of currentvoltage curves and measurement of tail current reversal potentials showed that $E_{\mathrm{R}}$ was fairly constant from fiber to fiber, typically between -25 and $-30 \mathrm{mV}$, and that $E_{\mathrm{R}}$ was stable during current measurements.

The second source of error, variation in fiber size, was reduced by normalizing $\mathrm{G}$ to membrane area as measured by membrane capacitance. Application of a "sawtooth" command to a voltage-clamped membrane yielded current records in which the capacitative and ionic components could be easily separated (Fig. 1). When the approximate slope conductances of the 11 Oregon $R$ fibers were normalized to their individual membrane capacitances, the average was $1.53 \times 10^{3} \pm 0.25 \mathrm{~S} / \mathrm{f}$, an error of $16 \%$. Normalizing to membrane capacitance thus reduced the $\mathrm{SD}$, although there was still significant variation in the values of S/f. Figure 1 shows an example of the calculation of approximate chord conductance and membrane capacitance for 1 fiber. Membrane capacitance has been converted to area by assuming $1 \mu \mathrm{f} / \mathrm{cm}^{2}$. For convenience the symbol $\Gamma$ will be used for slope conductance normalized to membrane area.

\section{Dosage compensation and gene dosage}

Of the Oregon $R$ fibers that make up the wild-type sample, 6 were from male pupae and 5 from females. The values of $\Gamma$ for males, $1.59+0.27 \mathrm{mS} / \mathrm{cm}^{2}$, and for females, $1.46 \pm 0.23 \mathrm{mS} /$ $\mathrm{cm}^{2}$, were not significantly different. The values of $\Gamma$ for $B 55^{\mathrm{D}} /$ $B^{\text {SP }}$ males and $C(I) A$ females, which share the same autosomal background, were likewise similar (Table 1). The Shaker locus is therefore dosage compensated in males.

To test whether A current varies as gene dosage, we measured $\Gamma$ in pupae with $1,2,3$, and the equivalent of 4 copies of $S h^{+}$
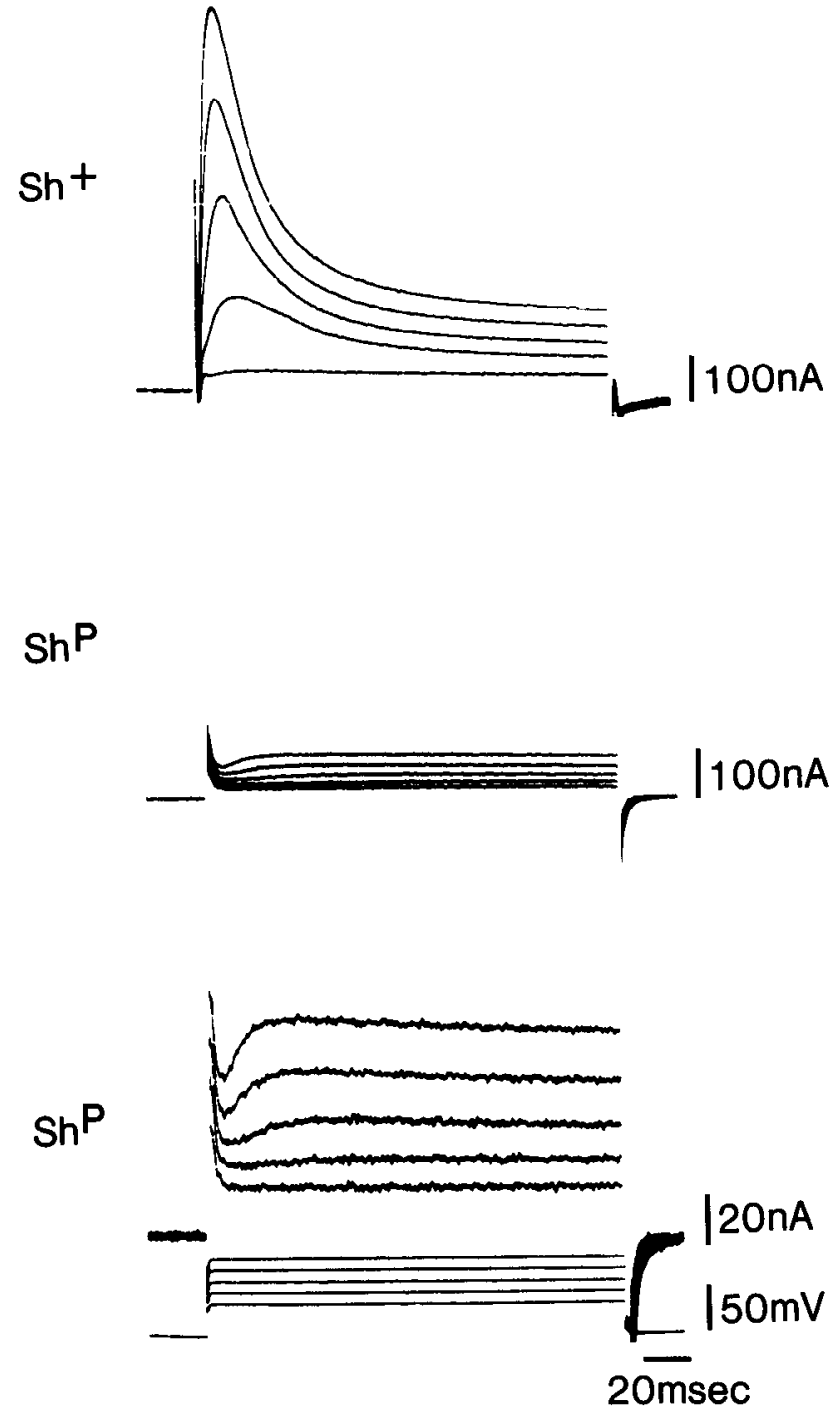

Figure 3. Shaker ${ }^{\mathrm{P}}$ lacks the fast component of transient outward current, but has a small, residual current. The quickly inactivating current present in $S h^{+}$(upper traces) is complctcly missing from $S h^{\mathrm{P}}$ (middle traces). Lower traces, At a higher gain, the residual current is seen to begin to inactivate. For each set of current traces the command protocol is the same, a series of voltage jumps from the holding potential of -70 $\mathrm{mV}$ to a test potential between -35 and $+5 \mathrm{mV}$ (see voltage traces at the bottom of the figure).

(Table 1). For 1 copy of $S h^{+}$in a female there was a significant reduction in $\Gamma$ compared to females with 2 copies or to males with a single copy. This decrease in $\Gamma$, from $1.53 \pm 0.25 \mathrm{mS} /$ $\mathrm{cm}^{2}$ to $1.02 \pm 0.31 \mathrm{mS} / \mathrm{cm}^{2}$, is significant $(p<0.0005, t=4.17$, $19 d f$, 1 -tailed $t$ test). This reduction is not as great as would be expected if gene dosage were followed strictly, however; in that case, $\Gamma$ should be about half the control level, or $0.77 \mathrm{mS} / \mathrm{cm}^{2}$. In contrast, extra copies of $S h^{+}$failed to cause a significant increase in $\Gamma$. This result is seen most clearly in males of genotype $\left(T(1,4) B^{\mathrm{sP}}\right) / X$, in which the 2 copies of $S h^{+}$should be dosage compensated to give the equivalent of 4 copies in females. Yet the value of $\Gamma, 1.68 \pm 0.48 \mathrm{mS} / \mathrm{cm}^{2}$, was not significantly different from the value in the Oregon $R$ controls, $1.53 \pm 0.25$ $\mathrm{mS} / \mathrm{cm}^{2}$. If the size of the A current followed gene dosage, $\Gamma$ should have a value of nearly $3 \mathrm{mS} / \mathrm{cm}^{2}$. Likewise, there was no increase in $\Gamma$ in pupae with 3 doses of $S h^{+}$compared to their 


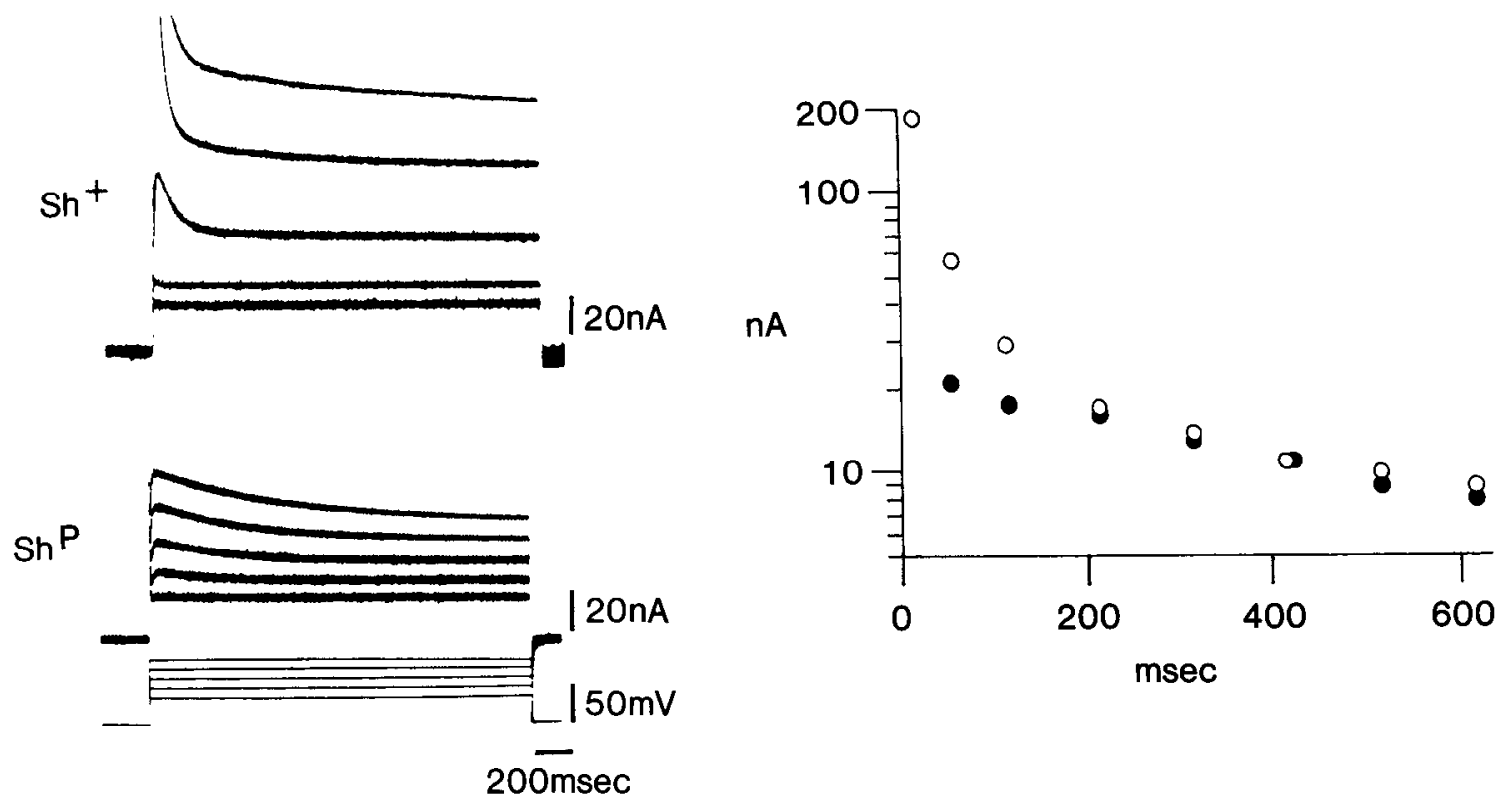

Figure 4. A slowly inactivating component of outward current is also present in $S h^{+}$. Left, In $S h^{+}$the transient outward current has a large, rapidly inactivating component and a small component that inactivates more slowly. For the 2 largest voltage jumps, the peak of the fast component is off scale. The residual current in $S h^{\mathrm{p}}$ inactivates at about the same rate as the slow component in $S h^{+}$. Right, A semilogarithmic plot of current against time shows that both the residual current in $S h^{\mathrm{P}}$ (closed circles) and the slow component of $S h^{+}$(open circles) decay exponentially with a time constant of about $550 \mathrm{msec}$. In $S h^{+}$there is also a large, fast component, which inactivates with a time constant of about $20 \mathrm{msec}$. Holding potential, $-70 \mathrm{mV}$; test potential, $+5 \mathrm{mV}$.

$C(I) A$ control (Table 1). While reducing the dosage of $S h^{+}$from 2 to 1 in females reduced $\Gamma$, there was no significant change in the rate of A current inactivation: $\tau$ for jumps to $38 \pm 1 \mathrm{mV}$ was $17.7 \pm 5.7 \mathrm{msec}$ in Oregon $R$ controls and $15.2 \pm 4.4 \mathrm{msec}$ in deficiency/Sh+ hetcrozygotes. In summary, varying the number of copies of $S h^{+}$produces a change in the amplitude of the A current only when the dosage of $S h^{+}$is reduced below the normal level (Fig. 2).

\section{Mutant phenotypes}

The phenotypes of 14 Shaker mutants, some known and some previously undescribed, fall into 3 classes: the first class comprises 10 mutants that have no fast, transient, outward current in the pupal flight muscle (Table 2). In each of these 10 mutants, however, there is a small residual outward current that inactivates much more slowly. Current records from one of these mutants, $S h^{\mathrm{P}}$, are shown in Figures 3 and 4 . When the inactivation of outward current is approximated by a first-order process, the time constant for the fast component present in $\mathrm{Sh}^{+}$ is about $20 \mathrm{msec}$ for voltage jumps to $0 \mathrm{mV}$. For the slowly inactivating residual current, the time constant is about 500 msec. The residual current is therefore not simply reduced A current, because these 2 currents are kinetically distinct.

The residual current probably does not flow through a population of A channels whose rate of inactivation has been altered by the mutational event. If the residual current were the result of such a neomorphic mutation, it should be absent from wildtype flight muscle and present only in mutants. The transient outward current of $\mathrm{Sh}^{+}$flight muscle does, however, have 2 components of inactivation, the slower being comparable in rate to the residual current seen in mutants (Fig. 4). It was not possible to eliminate selectively the fast component from wild-type, because 4-aminopyridine (4-AP) at $5 \mathrm{~mm}$ was equally effective in blocking both components. Double-pulse experiments, which exploit the large difference in rates of inactivation, reduce the amplitude of the fast component but do not eliminate it. Nevertheless, the presence of the slow component in wild-type fibers suggests that the residual current seen in $S h^{\mathrm{P}}$ is also present in wild-type muscle fibers. The cffect of the mutation in $S h^{\mathrm{p}}$ therefore appears to be to eliminate completely 1 of 2 components

Table 2. Shaker mutants studied

\begin{tabular}{lll} 
Mutation & Nature of mutagenesis & $\begin{array}{l}\text { Phenotype } \\
\text { in pupal } \\
\text { muscle }\end{array}$ \\
\hline $\mathrm{T}(\mathrm{X} ; \mathrm{Y}) \mathrm{W} 32=16 \mathrm{~F} 3-6$ & $\mathrm{X}$-ray & Null $^{a}$ \\
$\mathrm{~T}(\mathrm{X} ; 3) \mathrm{Sh}^{\mathrm{LC}}=16 \mathrm{~F} 1-2 ; 80$ & $\mathrm{X}$-ray & Null $^{a}$ \\
$\mathrm{~T}(\mathrm{X} ; \mathrm{Y}) \mathrm{B} 55=16 \mathrm{~F} 1-4$ & $\mathrm{X}$-ray & Leaky $^{a}$ \\
$S h^{\mathrm{KS} 133}$ & Ethyl methanesulfonate & Null $^{a}$ \\
& (EMS) & \\
$S h^{102}$ & EMS & Null \\
$S h^{\mathrm{E} 62}$ & EMS & Leaky \\
$S h^{\mathrm{SB2}}$ & Spontaneous & Null \\
$S h^{\mathrm{SB3}}$ & p element & Leaky \\
& hybrid dysgenesis & \\
$S h^{\mathrm{SB} 13}$ & Spontaneous & Null \\
$S h^{\mathrm{K} 83 \mathrm{r}}$ & p element & Null \\
& hybrid dysgenesis & \\
$S h^{\mathrm{K} 82 \mathrm{a}}$ & $\gamma$-ray & Null \\
$S h^{\mathrm{K} 82 \mathrm{~b}}$ & $\gamma$-ray & Null \\
$S h^{\mathrm{P}}$ & $\gamma$-ray & Null \\
$S h^{\text {K } 0120}$ & EMS & Leaky \\
\hline
\end{tabular}

${ }^{a}$ Salkoff (1983b).

${ }^{b}$ Jan et al. (1983)

${ }^{c}$ See Materials and Methods. 

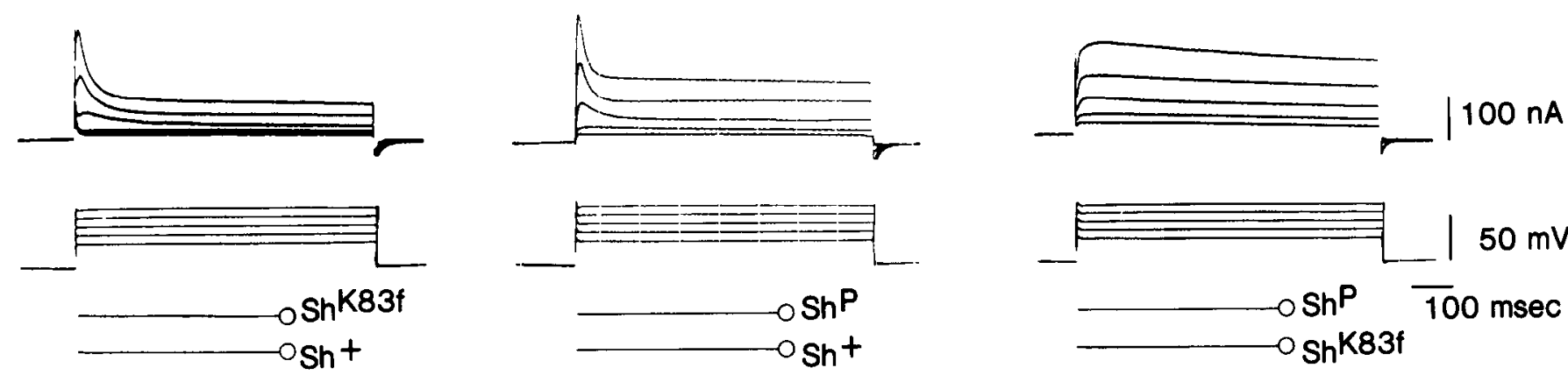

Figure 5. $S h^{\mathrm{P}}$ and $S h^{\mathrm{k} 83 \mathrm{r}}$ do not complement for A current. The $S h^{\mathrm{P}} / S h^{+}$and $S h^{\mathrm{k83}} / S h^{+}$controls show significant amounts of A current, whercas the $S h^{\mathrm{P}} / S h^{\mathrm{K} 83 \mathrm{f}}$ fiber has no A current. The slowly inactivating current is clearly present in $S h^{\mathrm{P}} / S h^{\mathrm{K} 83 \mathrm{f}}$. For the complementation experiments in general, each null mutant was tested against $S h^{102}, S h^{\mathrm{k} 83 f}$, and $S h^{\mathrm{k} 82 \mathrm{a}}$. In these experiments at least 2 fibers were examined for A current in each heterozygotic genotype. For most genotypes, 4 fibers were examined in 2 or more pupae. None of these experiments revealed any A current in the heterozygotes.

of the total transient outward current. We refer to $S h^{\mathrm{P}}$ and to the 9 similar mutations as "nulls" for A current.

The slowly inactivating current is present in each of the 10 null mutations. This observation provides further evidence that the residual current is not due to an alteration in the A channel's propertics, since the chance that a mutational cvent would produce a null phenotype should be greater than the chance it would produce a functioning channel with new electrophysiological characteristics. Although the residual current is present and its size is consistent in fibers of the same genotype, the amplitude varies in the different null strains. Compare, for example, $S h^{\mathrm{P}}$ in Figure 3 with its fairly large residual current to $S h^{102}$ in Figure 8 , where the current could be seen only at much higher gain. The reason for this variability is not understood; one possibility is that it is due to the different genetic backgrounds of the mutants.

The residual outward current is distinct from the delayed rectifier, or $\mathrm{K}$ current, both kinetically and pharmacologically. For a jump to $0 \mathrm{mV}$ at $12^{\circ} \mathrm{C}$, the slowly inactivating current rises to its peak more rapidly than does the $\mathrm{K}$ current, with a

\begin{tabular}{lll}
\hline Table 3. & A current amplitude in some $\boldsymbol{S} \boldsymbol{h} / \boldsymbol{S} \boldsymbol{h}^{+}$heterozygotes \\
Mutation & A current in $S h / S h$ & A current in $S h / S h^{+}$ \\
\hline$S h^{\mathrm{KS} 133}$ & 0 & $54 \%$ \\
& & $( \pm 14 \%, n=12)$ \\
$S h^{102}$ & 0 & $52 \%$ \\
& & $( \pm 18 \%, n=8)$ \\
$S h^{\mathrm{K} 82 \mathrm{a}}$ & 0 & $83 \%$ \\
& & $( \pm 10 \%, n=8)$ \\
$\mathrm{B} 55$ & $21 \%$ & $103 \%$ \\
& $( \pm 6 \%, n=4)$ & $( \pm 19 \%, n=7)$ \\
$S h^{\mathrm{E} 62}$ & $27 \%$ & $84 \%$ \\
& $( \pm 16 \%, n=11)$ & $( \pm 15 \%, n=9)$ \\
$S h^{\mathrm{5B3}}$ & $38 \%$ & $96 \%$ \\
& $( \pm 11 \%, n=9)$ & $( \pm 33 \%, n=12)$ \\
$S h^{\mathrm{rK} 0120}$ & $63 \%$ & $136 \%$ \\
& $( \pm 12 \%, n=8)$ & $( \pm 47 \%, n=13)$
\end{tabular}

The values listed arc percentages of the average peak $A$ current in wild-type, with errors reported in SD. Peak A currents were measured for jumps from a holding potential of $-70 \mathrm{mV}$ at $0 \mathrm{mV}$. The baseline was the level of current $80 \mathrm{msec}$, about 4 time constants, after the peak. For wild-type (Oregon R), the mean peak A current was $251 \pm 101 \mathrm{nA}, n=12$. These values have not been normalized to membrane area. time to half-peak of about $15 \mathrm{msec}$ compared to about $45 \mathrm{msec}$. The slowly inactivating current also inactivates on a time scale in which the $\mathrm{K}$ current shows no inactivation. Tetraethylammonium ion, which at $10 \mathrm{~mm}$ reduces steady-state $\mathrm{K}$ current by roughly half, has little effect on the slowly inactivating current.

\section{The null mutations do not complement}

Because of an earlier report that the genetic organization of Shaker is complex (Tanouye et al., 1981), we were interested to learn whether the mutants with the null phenotype identified more than 1 complementation group. Figure 5 shows the result of a complementation test between $S h^{\mathrm{k} 83 \mathrm{f}}$ and $S h^{\mathrm{P}}$. While the 2 control fibers of genotypes $S h^{\mathrm{K} 83 \mathrm{f}} / S h^{+}$and $S h^{\mathrm{P}} / S h^{+}$had significant A current, the $S h^{\mathrm{P}} / S h^{\mathrm{K} 83 \mathrm{f}}$ heterozygote had none. The slowly inactivating outward current was clearly present in the $S h^{\mathrm{P}} /$ $S h^{\mathrm{K} 83 \mathrm{f}}$ fiber, however. In similar experiments, each of the other null mutants was tested against $S h^{\mathrm{K} 83 \mathrm{f}}, S h^{102}$, and $S h^{\mathrm{K} 82 \mathrm{a}}$. In every case there was no A current. Therefore, these 10 null mutations form a single complementation group.

The interpretation of these complementation experiments depends on the null alleles being either recessive or incompletely dominant. For all 10 alleles $S h / S h^{+}$heterozygotes have easily detectable A current in pupal muscle. The degree of dominance in 3 of these alleles is shown in Table 3. Shaker ${ }^{\mathrm{KS} 133}, S h^{102}$, and $S h^{\mathrm{K} 82 \mathrm{a}}$ are all partially dominant, with $S h / S h^{+}$heterozygotes producing about $50-80 \%$ of the normal amount of current. Crosses between these null mutants should reveal complementation if more than one complementation group is present, sincc as little as $5 \%$ of the normal A current would be apparent in these experiments.

\section{Mutations that reduce $A$ current amplitude}

Three of the 14 Shaker mutants have A current, but the peak amplitude is significantly smaller than in wild-type. The $S h^{\text {sB3 }}$ mutation has about $40 \%$ normal A current, $S h^{\mathrm{E} 62}$ aboul $30 \%$, and $B 55$ [a translocation, $T(1 ; Y) B 55=16 F 1-4$ ] about $20 \%$. Each of these "leaky" mutations is recessive (Table 3 ). Although the peak A current is reduced in homozygotes, the threshold for current activation and the time constant of inactivation, about $20 \mathrm{msec}$ for jumps to $0 \mathrm{mV}$, are the same in these mutants as in wild-type. 4-AP blocks these reduced A currents as effectively as it blocks normal A current. Thus, 1 or more of these leaky mutants may produce normal A channels, but in reduced num- 
A

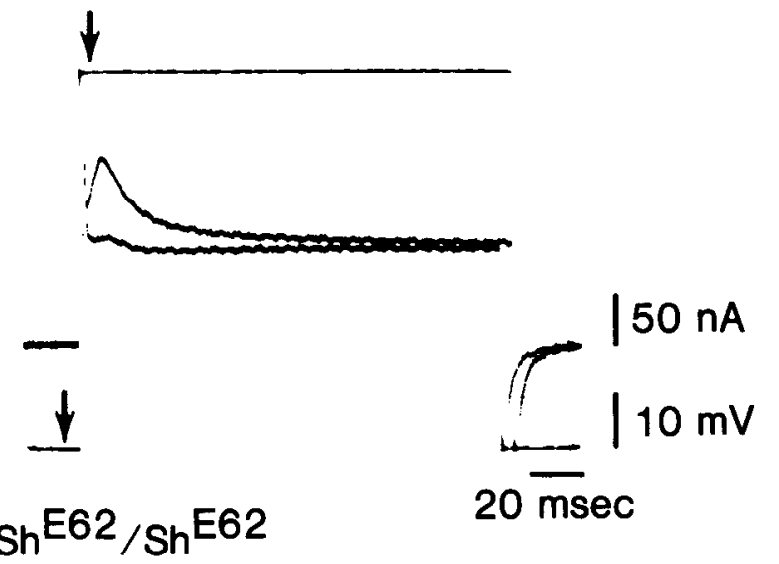

C

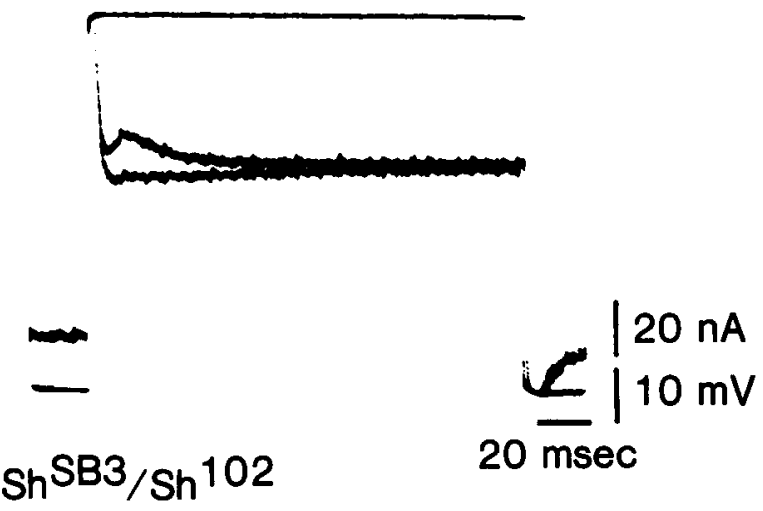

B
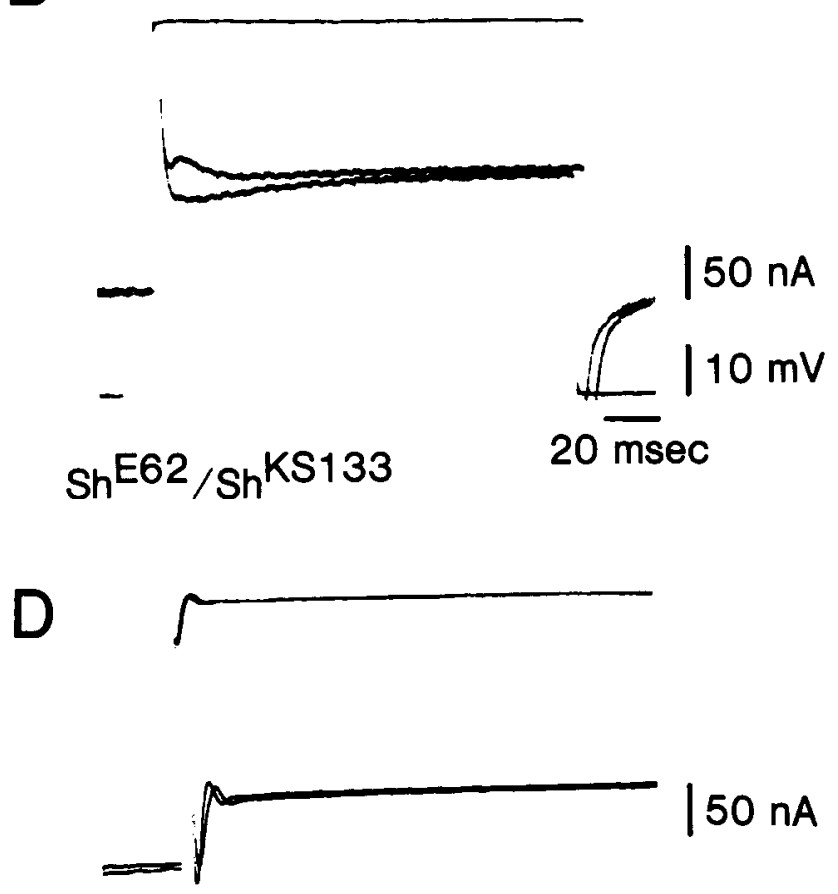

$\mathrm{Sh}^{\mathrm{E} 62} / \mathrm{Sh}^{102}$

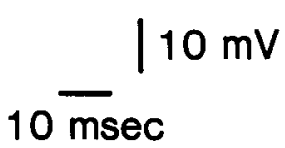

Figure 6. Negative complementation between $S h^{\mathrm{E} 62}$ and $S h^{102}$. Each panel shows voltage and current traces; arrows in $A$ indicate membrane potential just before and just after the jump. In each experiment, 2 jumps from -70 to $0 \mathrm{mV}$ were made with an interval of about 50 msec. The inactivating process that turned off the A current during the first jump persisted, so that during the second jump the A current was largely eliminated. The amplitude of the A current can be estimated from the difference between the 2 current traces. No A current could be detected in the $S h^{\mathrm{E} 62} /$ $S h^{102}$ heterozygote $(D)$, although A current was clearly present when $S h^{\mathrm{E} 62}$ was tested against a different null mutation $(B)$ or when $S h^{102}$ was tested against a different leaky mutation $(C)$.

bers; such a mutant would be a hypomorph (Muller, 1932). Alternatively, the A currents in these mutants could differ from wild-type A currents in ways that have not been detected.

To test for complementation of the A current, we made crosses between each of the 3 leaky mutants and 1 or more null mutations. In general, the $S h^{\text {leaky }} / S h^{\text {null }}$ heterozygotes had smaller A currents than did their homozygous $S h^{\text {leaky }}$ parental lines, as would be expected if the leaky mutants were in the same complementation group as the nulls. In most cases, the significance of the size of these currents was difficult to interpret, given the large SD in current measurements. In the $S h^{\mathrm{E} 62} / S h^{102}$ heterozygote, however, there was an unexpected result: no A current could be detected at all (Fig. 6). This effect is specific for the interaction between these 2 alleles, since $A$ current could be seen in both $S h^{\mathrm{E} 62} / S h^{\mathrm{KS} 133}$ heterozygotes and in $S h^{\mathrm{SB} 3} / S h^{102}$ heterozygotes. This example of "negative" complementation suggests that $S h^{\mathrm{E} 62}$ is allelic with $S h^{102}$, and hence with the other null mutations.

\section{Cytological location of Shaker}

Because $B 55$ is a translocation breakpoint mutation, it was possible to learn whether the distal (relative to the centromere) or the proximal fragment of the $B 55 X$ chromosome carries Shaker. Male pupae of the genotype $S h^{102} / B 55^{\mathrm{P}}$ were found to have small
A currents, about 5\% of the normal level (Fig. 7). Assuming there has been no secondary rearrangement of $B 55^{\mathrm{P}}$, this complementation of the A current suggests either that the entire Shaker locus is proximal to the $B 55$ breakpoint or, if that breakpoint occurs within Shaker, that tue region proximal to the $B 55$ breakpoint is sufficient to produce a functioning Shaker product. This result is consistent with an earlier experiment, in which it was shown that a male pupa of genotype $B 55^{\mathrm{D}}-W 32^{\mathrm{P}}$ lacks $\mathrm{A}$ current, whereas a $W 32^{\mathrm{D}}-B 55^{\mathrm{P}}$ male does have A current (Salkoff, 1983b).

Another translocation breakpoint, $T(1 ; Y) V 7$, sets a boundary for Shaker in the centromeric direction. $V 7$ males do not shake under ether anesthesia; A current is present in their pupal flight muscle. Since pupae of genotype $V 7^{\mathrm{D}}-W 32^{\mathrm{P}}$ also have A currents, Shaker must lie distal to the $V 7$ breakpoint. The region required for the production of the Shaker gene product therefore lies between the $B 55$ and the $V 7$ breakpoints. The cytological locations of these breakpoints have been reported as 16F1-4 and $16 F 5-8$ for $B 55$ and $V 7$, respectively, (Tanouye et al., 1981; (I. Duncan, personal communication).

\section{ShakerrKonso}

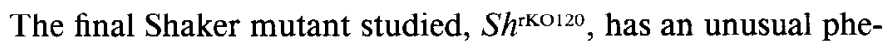
notype. These flies have a large A current in pupal muscle, about 

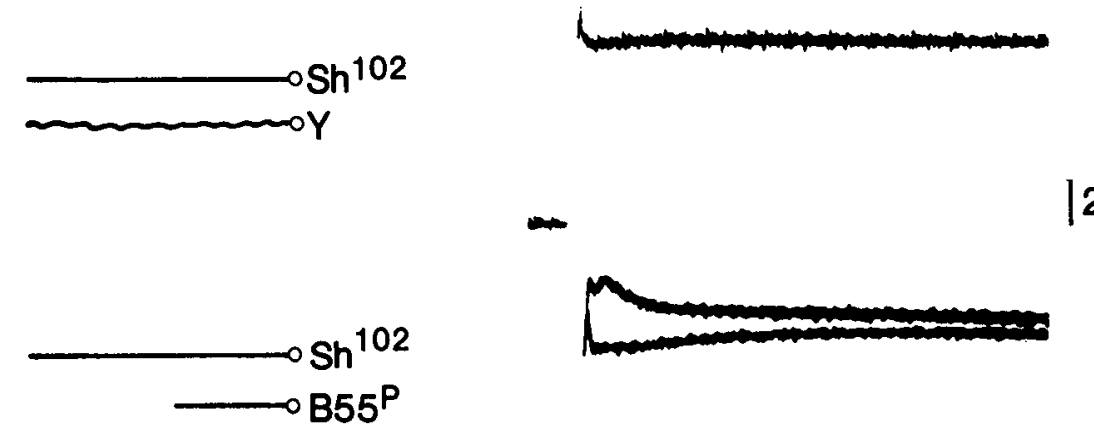

$120 \mathrm{nA}$

Figure 7. The Shaker locus is proximal to the $B 55$ breakpoint. Upper traces, Current records from a $S h^{102}$ male, 2 identical voltage jumps with a $50 \mathrm{msec}$ interval. There is no A current. Lower traces, Current records from a $S h^{102} /$ $B 55^{\mathrm{P}}$ male. A small A current is present. Two voltage jumps were given, with an interval of $50 \mathrm{msec}$. During the second jump the A current was still largely inactivated. The A current in this fiber is about $8 \%$ of the level in wild-type; this measurement was near the limit of sensitivity.

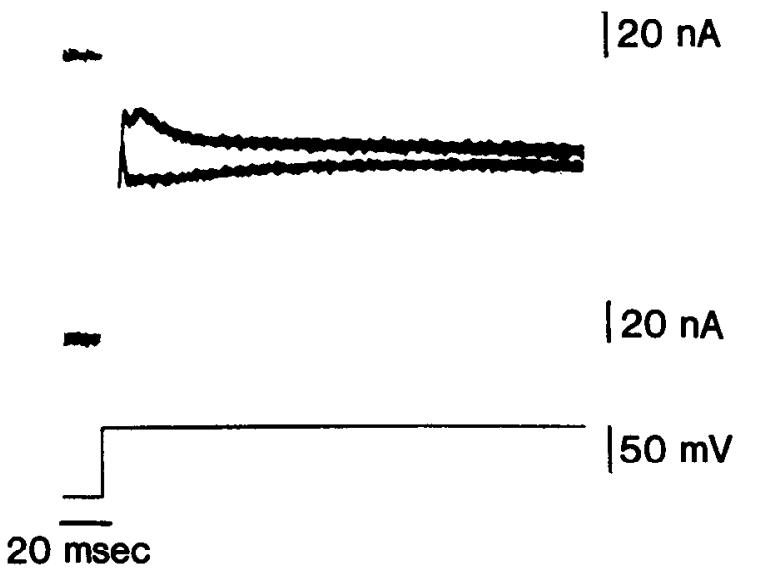

$60 \%$ of wild-type (Table 2). Synaptic transmission at the larval neuromuscular junction, however, is as severely abnormal as in the null mutants (Fig. 8).

The mutant phenotype at the larval neuromuscular junction is characterized by synaptic transmission in saline containing $5 \times 10^{-5} \mathrm{M} \mathrm{Ca}^{2+}$, a concentration too low to support transmission in wild-type larvae (Jan et al., 1977). This phenotype is thought to be due to a defect in voltage-sensitive potassium channels in the membrane of the motoneuron's axonal terminals. The strength of the phenotype varies among the different Shaker mutants. Each of the 10 nulls has a "strong" phenotype, in which the first or second nerve stimulus in a series at $1 \mathrm{~Hz}$ elicits an excitatory junctional potential (ejp). In contrast, the mutants with reduced A current- $S h^{\mathrm{E} 62}, S h^{\mathrm{SB} 3}$, and $B 55$-have a "moderate" phenotype: several seconds of nerve stimulation at $4 \mathrm{~Hz}$ are required before small ejps appear; these then facilitate (see Jan et al., 1983, for a comparison of the phenotypes). Shaker ${ }^{\mathrm{K} O 120}$ has the same strong phenotype at the larval neuromuscular junction as do the null mutants (Fig. 8). Judging from the strength of its phenotype, $S h^{\text {rKO120 }}$ should have as little A current in its motor axon terminals as do the nulls. Surprisingly, it has about $60 \%$ of normal A current in pupal muscle.

Is the apparent discrepancy in phenotype between pupal muscle and larval neuromuscular junction due to the difference in developmental stage or to the difference in tissue? To answer this question we examined a third preparation, the body wall muscle fibers of third instar larvae. Using voltage-clamp techniques the A current may be studied in larval muscle (Wu et al., 1983a). The result was similar to that found in pupal flight muscle: Fibers from $S h^{\text {rKO120 }}$ larvae have A current, while fibers from $S h^{102}$ lack it. A similar finding has been reported by Wu and Haugland (1985), who observed the A current in larval muscle of $S h^{\text {rKO120 }}$ but not in $S h^{\mathrm{KS} 133}$ or $S h^{102}$. Thus, in $S h^{\text {rKO120 }}$ there is a discrepancy in phenotype between larval nerve and muscle in both larvae and pupae, suggesting that this mutation may discriminate between tissues and reduce the expression of the Shaker product more severely in the motor axon than in the muscle.

Given the large difference in phenotypes between $S h^{\text {roO120 and }}$ the null mutants in pupal flight muscle, we wondered whether $S h^{\text {rKo120 }}$ identifies a new complementation group. In crosses of
$S h^{\text {rKO120 }}$ against $S h^{\mathrm{K} 82 \mathrm{a}}$ and $S h^{102}$, however, there was no complementation of the abnormally large excitatory junctional potential at the larval neuromuscular junction. Larvae of the genotypes $S h^{\text {rKO120}} / S h^{\mathrm{K} 82 \mathrm{a}}$ and $S h^{\text {rKO120/ }} S h^{102}$ have the same strong mutant phenotypes as homozygous larvae of the parental genotypes. The control larvae- $S h^{\mathrm{rkO120}} / S h^{+}, S h^{\mathrm{k82a} /} S h^{+}$, and $S h^{102 /}$ $S h^{+}-$have very mild phenotypes, verging on wild-type. By this test, therefore, $S h^{\mathrm{rKO} 120}$ is allelic with the other Shaker mutations.

\section{Discussion}

Mutations of the Shaker locus affect a voltage-sensitive potassium channel, the A channel, in Drosophila. Because genetic and molecular studies of Shaker may provide a way to analyze the $A$ channel and its expression, we thought that it would be important to test whether the A current is proportional to gene dosage, as would be expected if Shaker were the structural gene for the A current. In fact, the amplitude of the A current is significantly reduced for 1 copy of $S h^{+}$in a female, but fails to incrcasc for extra copies. We also hoped to define the Shaker locus better genetically by examining membrane currents in a large group of Shaker mutants. The 14 mutants studied here fall into 2 classes: those with no detectable A current and those with an A current of reduced amplitude. One of the mutants with reduced A current, $S h^{\text {rKO120 }}$, is unusual; homozygous $S h^{\text {rKO } 120}$ has an unexpectedly severe mutant phenotype at the larval neuromuscular junction, as compared to its mild phenotype in pupal muscle. The 10 mutants with no detectable A current are all members of a single complementation group, suggesting that they affect a single polypeptide chain. That part of the Shaker locus required for the production of the A channel lies in region $16 \mathrm{~F}$ of the $X$ chromosome, bounded distally by the $B 55$ and proximally by the $V 7$ translocation breakpoints.

\section{A current measurements and gene dosage}

Since the gene-dosage experiments required a measure of the Shaker phenotype, it was necessary to determine the amplitude of A currents accurately. We found the 2 most important factors to be (1) making the measurements in $72 \mathrm{hr}$ pupae, in which there is no $\mathrm{K}$ current superimposed on the A current (Salkoff and Wyman, 1981a), and (2) normalizing the current to membrane area. Measuring the $A$ current in the presence of K current 


$\begin{array}{cc}\text { LARVAL } & \text { PUPAL } \\ \text { NEUROMUSCULAR } & \text { FLIGHT } \\ \text { JUNCTION } & \text { MUSCLE }\end{array}$

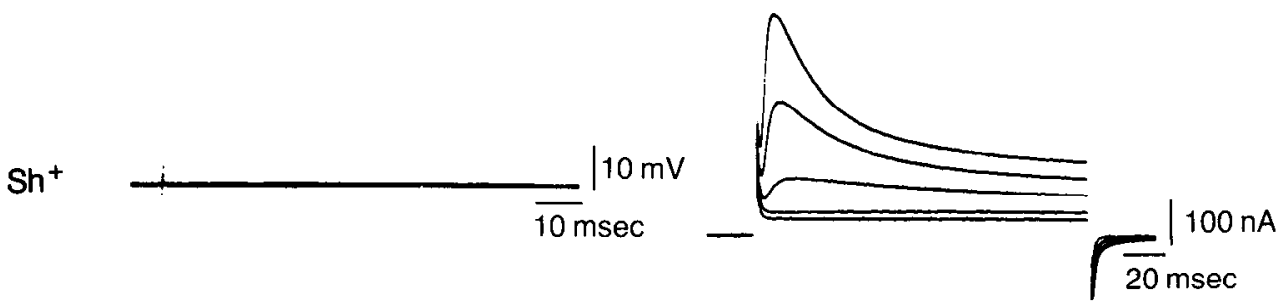

$\operatorname{Sh}^{102}$
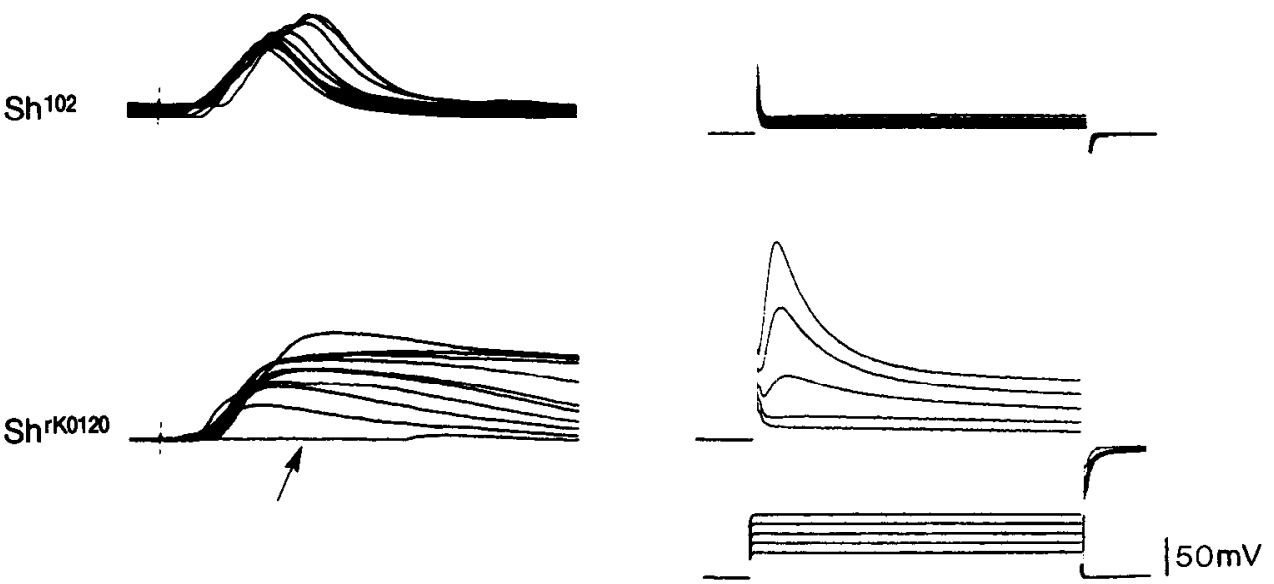

Figure 8. Shaker rKO120 has the phenotype of a null mutation at the larval neuromuscular junction but has a large A current in pupal muscle. Left column, Synaptic transmission in $5 \times 10^{-5} \mathrm{M}$ $\mathrm{Ca}^{2+}$. Motoneurons were stimulated extracellularly at $1 \mathrm{~Hz}$; the excitatory junctional potentials (ejp) were recorded intracellularly from larval muscle fibers (see Materials and Methods). Transmission fails in $S h^{+}$but succeeds in $S h^{102}$ and after the first stimulus (ar-

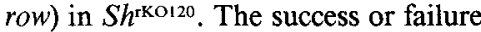
of the first stimulus, as well as the duration of the ejp, varies among fibers of the same larva. When many fibers are compared, the phenotypes of $S h^{\text {rKO120 }}$ and $S h^{102}$ are indistinguishable. Right column. A current is present in pupal muscle of $S h^{\text {rKO120 }}$, about $60 \%$ of wildtype (Table 3). has been particularly misleading. In an earlier report we found no difference between the A currents in $S h^{\mathrm{E} 62}, S h^{\mathrm{SB} 3}$, and $S h^{+}$, judging from experiments with older pupae (Jan et al., 1983, figures 5,7$)$. Yet $S h^{\mathrm{E} 62}$ and $S h^{\mathrm{BB} 3}$ clearly have less A current than $\mathrm{Sh}^{+}$in $72 \mathrm{hr}$ pupae. The K current is a poor standard for normalizing A current, since its amplitude increases rapidly during the final day of pupal development.

In eukaryotic biochemical genetics a correlation between the number of copies of a gene and the activity of an enzyme is taken as evidence that the gene is a structural gene for that enzyme. The demonstration of strict gene-dosage dependence does not prove that a gene is structural, however, since it is possible that the product of a second, modifying, gene may be required stoichiometrically with the product of a structural gene. Nevertheless, in Drosophila those genes that have strong genedosage effects have all becn shown by other critcria to be structural genes (O'Brien and MacIntyre, 1978). The experiments reported here demonstrate that with 1 copy of $S h^{+}$in a female there is a moderate reduction in A current amplitude compared to wild-type but that with 3 copies in a female or 2 copies in a male there is little increase in A current. The proximal element of $T(1 ; 4) B^{\mathrm{s}}$, which was used to supply an extra copy of $S h^{+}$in males and females, also carries Zwischenferment, the structural gene for glucose-6-phosphate dehydrogenase. Bowman and Simmons (1973) have shown that females and males that carry the proximal element of $T(1 ; 4) B^{\mathrm{s}}$, in addition to their normal sex chromosomes, have roughly 150 and $200 \%$ of the normal glucose-6-phosphate dehydrogenase activity, respectively. Thus, the copy of $S h^{+}$on the proximal element of $T(1 ; 4) B^{\mathrm{s}}$ should be able to increase the amount of the Shaker gene product as well. Since the amplitude of the A current does not increase with the dosage of $S h^{+}$, these results provide only weak support for the hypothesis that Shaker is a structural gene for the A channel. A better understanding of the relation between the Shaker gene product and the A channel will require other experimental approaches.

By itself the reduction in A current seen with 1 copy of $S h^{+}$ is consistent with Shaker being a structural gene. If this is the case, the results with extra copies of $S h^{+}$suggest that there is an upper limit imposed on A-current density in the muscle fiber's membrane. Tanouye et al. (1981) and Salkoff (1983b) have proposed that there may be a finite number of membrane sites for A channels, which could limit current density. Alternatively, the number of functioning A channels may be limited by the amount of another peptide subunit of the A channel, if that subunit were the product of a locus different from Shaker, one that was not varied in the gene-dosage experiments. Finally, the number of functional channels may be regulated posttranscriptionally.

\section{The location of Shaker}

Since the $B 55^{\mathrm{P}}$ and the $V 7^{\mathrm{D}}$ fragments complement mutations null for the $A$ current, the region between these breakpoints must include the nucleotide sequences necessary for the production of a functional Shaker gene product. This result does not exclude the possibility that some controlling or regulatory regions of Shaker lie outside the breakpoints. The $B 55$ breakpoint, for example, may occur in a regulatory region, thereby reducing the expression of the Shaker product. Alternatively, the $B 55$ breakpoint could lie beyond Shaker and reduce expression by a position effect. We did not see the "variegation" in A-current amplitude that might be expected with a position 
effect; Tanouye et al. (1981) report that neither culturing the flies at high temperature nor the addition of an extra $Y$ chromosome alters the phenotypes of these breakpoint mutations. The $B 55$ breakpoint may therefore occur in a region important for controlling the expression of Shaker but distal to the region required for the synthesis of a functioning gene product.

An earlier investigation divided the Shaker locus into 2 parts, separated by a haplolethal region (Tanouye et al., 1981). Part of Shaker was thought to be proximal to the haplolethal region because the $V 7$ breakpoint lies proximal to this region and because $V 7$ was held to be a Shaker mutant. We have found no evidence for a Shaker phenotype in $V 7$ flies. Our experiments have shown that the distal fragment of $V 7$ carries the Shaker function and that the $V 7$ breakpoint must therefore lie outside the coding region. This result is consistent with a simpler view of the locus, in which there would be only 1 Shaker region rather than 2. Our conclusions differ from those of Tanouye et al. (1981) on another point. While these authors locate the $S h^{\mathrm{LC}}$ breakpoint distal to the $B 55$ breakpoint, we believe that it is likely to be proximal to $B 55$, since $B 55^{\mathrm{P}}$ supplies the Shaker function and since $S h^{\mathrm{LC}}$ is in the same complementation group as the other null mutations. A better understanding of the spatial disposition of Shaker and the translocation breakpoints may be obtained from studies of the locus at the molecular level.

\section{Null alleles and the residual outward current}

Ten of the 14 Shaker mutants are null for the A current, although in each of these 10 a small, more slowly inactivating current is present. A simple interpretation is that the null mutations uncover a small current normally obscured by A current. This residual current resembles the A current in being a transient, outward current and in its sensitivity to 4-AP. One puzzling feature of the residual current is the variation in its amplitude found in the different null alleles. Possibly this variation is due to differences in genetic background. Alternatively, the amplitude of the residual current may depend on a product of the Shaker locus or of a neighboring locus. A simple test of this hypothesis would be to look for the residual current in pupae deficient for the Shaker locus. There is no viable deficiency that unambiguously spans all of Shaker, however. The synthetic deficiency $B 55^{\mathrm{D}}-V 7^{\mathrm{P}}$, which should lack the sequences required for A current, is not viable. Whether the amplitude of the residual current depends on a gene product from Shaker or from a neighboring locus therefore remains unclear.

As there is no viable deficiency covering Shaker, we do not know whether the null phenotype found in 10 of the mutants is the same as would be seen in a deficiency. Mutations that give the null phenotype in homozygotes could be either amorphic or antimorphic. For 7 of the null mutations described here, there is no evidence bearing on the question of whether a gene product is made and, if so, whether that gene product interferes with the function of the wild-type product. In 3 cases, however, A current was measured in $S h^{\text {null }} / S h^{+}$heterozygotes: $S h^{\text {KS133/ }}$ $S h^{+}, S h^{102} / S h^{+}$, and $S h^{\mathrm{k} 82 \mathrm{a}} / S h^{+}$have 54,52 , and $83 \%$ of the wild-type A current, respectively (Table 3 ). These values should be compared to the value of $67 \%$ found in $S h^{\text {deniciency }} / S h^{+}$, which would be expected from amorphic mutations. There is some indication that the gene products of $S h^{\mathrm{KS} 133}$ and $S h^{102}$ may be antimorphs, since the $S h^{\mathrm{kS} 133} / S h^{+}$and $S h^{102} / S h^{+}$heterozygotes have less A current than does the $S h^{\text {deficiency }} / S h^{+}$heterozygote. Given the large SDs in the current measurements, however, it is also possible that these apparent reductions in A current are not significant. The negative complementation of the A current seen in the $S h^{\mathrm{E} 62} / S h^{102}$ heterozygote suggests that the $S h^{102} \mathrm{mu}$ tation produces a gene product; if so, that product is not strongly antimorphic when tested against the wild-type $S h$ gene product. Tanouye et al. (1981) have proposed that the $S h^{\mathrm{Ks} 133}$ gene product is an antimorph on the basis of its effect on action potential duration in the cervical giant fibers of adult flies.

\section{Leaky mutants}

The first example of a Shaker mutant with reduced A current, $B 55$, was discovered by Salkoff (1983b). Two more, $S h^{\mathrm{E} 62}$ and $S h^{\mathrm{SB} 3}$, have been identified here. Are these leaky mutants hypomorphs, or do they produce channels of altered structure that nevertheless retain some function? Initial comparisons with wildtype suggest that the $A$ currents in these leaky mutants have normal electrophysiological properties: they activate at the same potential, inactivate at about the same rate at $0 \mathrm{mV}$, and are blocked by 4-AP. To test rigorously whether these currents are hypomorphic or neomorphic, however, would require a more thorough examination of their electrophysiological characteristics, such as measurement of activation and inactivation kinetics over a wide range of potentials and measurement of ionic selectivity or of unitary channel conductance.

\section{Shaker ${ }^{\text {rKOI20 }}$}

With about $60 \%$ of the normal A current in pupal flight muscle, Shaker ${ }^{\text {rkol20 }}$ seems to be another leaky mutant. The severity of the mutant phenotype at the larval neuromuscular junction, however, which is the same as in the null mutations, implies that the reduction of potassium channels in the motoneuron is much more extreme than in muscle. Is this difference in phenotypes between the 2 preparations due to a difference in the tissue expressing the A channel or to a difference in developmental stage? The former possibility seems to be the case, since a significant A current is present in both larval and pupal muscle

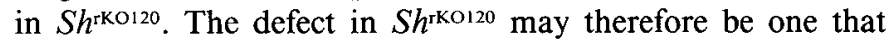
distinguishes between motoneuron and muscle fiber. A direct test of this hypothesis requires measuring the ionic currents of larval motoneuron under voltage clamp, which is technically difficult. Voltage-clamp techniques have been extended, however, to cultured larval neurons (Wu et al., 1983). Thus, it may be possible to study and compare the A currents of $S h^{\text {rKo120 }}$ and other mutations in primary cultures of larval neurons. It would also be interesting to see whether the Shaker product expressed in nerve is the same fast, transient A current found in muscle or whether in nerve it has different kinetic properties.

Our view of the phenotype of $S h^{\text {rko120 }}$ agrees with results reported by 2 other laboratories. Ganetzky and Wu (1983) have noted that the $S h^{\text {rKo120 }}$ allele, separated by recombination from a second mutation, has a phenotype at the larval neuromuscular junction similar to that of $S h^{\mathrm{KS} 133}$, a mutant that is null for A current. Wu and Haugland (1985) found the amplitude of $\mathrm{A}$ current in larval muscle to be the same in $S h^{\text {rKolzo }}$ as in $S h^{+}$, consistent with our observation of a large A current in $S h^{\text {rKO120 }}$ larval muscle. Our findings with pupal muscle differ, however, from those reported by Salkoff and Wyman (1981b). Where we found a large A current, roughly $60 \%$ of normal, Salkoff and Wyman (1981b) found none. Such a large discrepancy is probably due to differences in the stocks labeled "Shrko120," rather than to differences in technique. 


\section{Complementation}

The 10 null mutants fail to complement, suggesting that the mutations alter a single polypeptide. Shaker ${ }^{\text {leaky }} / S h^{\text {null }}$ heterozygotes have less A current than do the $S h^{\text {leaky }}$ parental strains, as would be expected if they were members of the same complementation group. In one case, the effect is extreme: the $S h^{\mathrm{E} 62}$ / $S h^{102}$ heterozygote has no detectable A current. This result is surprising, since heterozygotes made within $S h^{\mathrm{E} 62}$ and another null or heterozygotes made with $S h^{102}$ and another leaky mutation have A currents. One possible explanation for this negative complementation is that the gene products of both the $S h^{\mathrm{F}}$. 2 allcle and the $S h^{102}$ allele are abnormal and that they interact dysfunctionally within the A channel (Fincham, 1966). This proposal assumes that the A channel is a multimer, comprising more than 1 copy of the Shaker gene product. A test of this hypothesis, and of the more general question of the A channel's subunit structure, must await the isolation and purification of the A channel.

\section{References}

Begg, M., and W. J. Cruikshank (1962) A partial analysis of Drosophila larval haemolymph. Proc. R. Soc. Edinburgh [Biol.] 18: 215-236.

Bowman, J. T., and J. R. Simmons (1973) Gene modulation in Drosophila: Dosage compensation of $P g d^{\prime}$ and $Z w^{\prime}$ genes. Biochem. Genet. 10: 319-331.

Connor, J. A., and C. F. Stevens (1971) Voltage clamp studies of a transient outward current in gastropod neural somata. J. Physiol. (Lond.) 213: 21-30.

Fincham, J. R. S. (1966) Genetic Complementation, W Benjamin, New York.

Ganetzky, B., and C.-F. Wu (1982) Drosophila mutants with opposing effects on nerve excitability: Genetic and spatial interactions in repetitive firing. J. Neurosphysiol. 47: 501-514.

Ganetzky, B., and C.-F. Wu (1983) Neurogenetic analysis of potassium currents in Drosophila: Synergistic effects on neuromuscular transmission in double mutants. J. Neurogenet. 1: 17-28.

Henderson, R., and J. H. Wang (1972) Solubilization of a specific tetrodotoxin binding component from garfish olfactory nerve membranes. Biochemistry $11:$ 4565-4569.

Jan, L. Y., and Y. N. Jan (1976) Properties of the larval neuromuscular junction in Drosophila melanogaster. J. Physiol. (Lond.) 262: 189214.

Jan, Y. N., L. Y. Jan, and M. J. Dennis (1977) Two mutations of synaptic transmission in Drosophila. Proc. R. Soc. London [Biol.] 198: 87-108.

Jan, L. Y., S. Barbel, L. Timpe, C. Laffer, L. Salkoff, P. O'Farrell, and Y. N. Jan (1983) Mutating a gene for a potassium channel by hybrid dysgenesis: An approach to the cloning of the Shaker locus in Drosophila. Cold Spring Harbor Symp. Quant. Biol. 48: 233-245.
Kaplan, W. D., and W. E. Trout III (1969) The behavior of four neurological mutants of Drosophila. Genetics 61: 399-409.

Lindsley, D. L., and E. H. Grell (1968) Genetic variations of Drosophila melanogaster. Carnegie Inst. Wash. Publ. No. 627.

Mishina, M., T. Tobimatsu, K. Imoto, K. Tanaka, Y. Fujita, K. Fukuda, M. Kurasaki, H. Takahashi, Y. Morimoto, T. Hirose, S. Inayama, T. Takahashi, M. Kuno, and S. Numa (1985) Location of functional regions of acetylcholine receptor $\alpha$-subunit by site-directed mutagenesis. Nature 313: 364-369.

Muller, H. J. (1932) Further studies on the nature and causes of gene mutations. In Proceedings of the Sixth International Congress of Genetics, D. F. Jones, ed., pp. 213-255, Brooklyn Botanical Garden, Menasha, WI.

Neher, E. (1971) Two fast transient current components during voltage clamp on snail neurons. J. Gen. Physiol. 58: 36-53.

Noda, M., S. Shimizu, T. Tanabe, T. Takai, T. Kayano, T. Ikeda, H. Takahashi, H. Nakayama, Y. Kanaoka, N. Minamino, K. Kangawa, H. Matsuo, M. A. Raftery, T. Hirose, S. Inayama, H. Hayashida, 'I. Miyata, and S. Numa (1984) Primary structure of Electrophorus electricus sodium channel deduced from cDNA sequence. Nature 312 : 121-127.

O'Brien, S. J., and R. J. MacIntyre (1978) Genetics and biochemistry of enzymes and specific proteins of Drosophila. In The Genetics and Biology of Drosophila, M. Ashburner and T. R. F. Wright, eds., pp. 395-551, Academic Press, London.

Salkoff, L. (1983a) Drosophila mutants reveal two components of fast outward current. Nature 302: 249-251.

Salkoff, L. (1983b) Genetic and voltage-clamp analysis of a Drosophila potassium channel. Cold Spring Harbor Symp. Quant. Biol. 48: 221231.

Salkoff, L., and R. Wyman (1981a) Outward currents in developing Drosophila flight muscle. Science 212: 461-463.

Salkoff, L., and R. Wyman (1981b) Genetic modification of potassium channels in Drosophila Shaker mutants. Nature 293: 228-230.

Salkoff, L., and R. Wyman (1983) Ion currents in Drosophila flight muscles. J. Physiol. (Lond.) 337: 687-709.

Stewart, B. R. (1973) The use of segmental aneuploidy as a genetic tool in Drosophila melanogaster. Ph.D. thesis, University of California, Los Angeles.

Tanouye, M. A., A. Ferrus, and S. C. Fujita (1981) Abnormal action potentials associated with the Shaker locus of Drosophila. Proc. Natl. Acad. Sci. USA 78: 6548-6552.

Weill, C. L., M. G. McNamee, and A. Karlin (1974) Affinity labeling of purified acetylcholine receptor from Torpedo california. Biochem. Biophys. Res. Commun. 61: 997-1003.

$\mathrm{Wu}, \mathrm{C}$.-F., and F. Haugland (1985) Voltage clamp analysis of membrane currents in larval muscle fibers of Drosophila: Alteration of potassium currents in Shaker mutants. J. Neurosci. 5: 2626-2640.

Wu, C.-F., B. Ganetzky, A.-X. Liu, and F. Haugland (1983a) Potassium currents in Drosophila: Different components affected by $\mathrm{mu}-$ tations of two genes. Science 220: 1076-1078.

Wu, C.-F., N. Suzuki, and M. M. Poo (1983b) Dissociated neurons from normal and mutant Drosophila larval central nervous systems in cell culture. J. Neurosci. 3: 1888-1899. 